\title{
沙伊奇柯夫博士對於地理瞍上的 幾個基本問題的意見
}

\author{
施 雅 風
}

絧者按: 䱢聯科學院地理研究所副所長沙伊奇柯大博士於 1952 年 7 月來到 中國, 在 中 國科學院泇助下, 研究考察萃東區地理, 並先後在北京、南宗、上海等地, 與中國地理學者 討論了許多地理學上的問題，其中茫干問題，如 “經湾地理學與自然地理學的關係”，“地理 分區的原则” 等, 各地所提, 幾乎完全相同, 沙伊奇柯夫同志丵逜些問題都作了明確的解答,

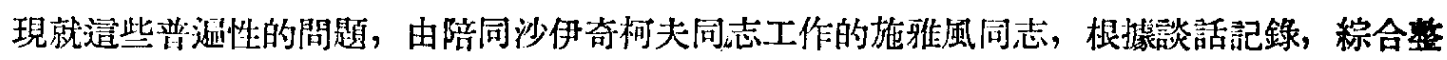
理，發表於此。沙仾奇柯夫同志已於 1952 年 12 月初回蘇聯，此稿未經他校閱。

\section{一、經濟地理翼與自然地理鼠的關係}

經富地理學與自然地理學是地理學中最大的 二個部門。這二部师地理學有共同的特點, 但也 有本質的偘别。其區别在於經济地理學的研究對

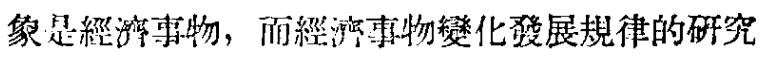
虚於社會科學範園，因此經湾地理學 是社會科 學; 自然地理學则是自然科學, 它底㸴究對象是 自然界，自然現象底變化發屡規律賞然不同於社

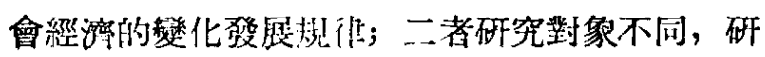
究的力法也就网樣。因此, 不能把自然地理與經 济地理混同第同一性筫的利學。

德國資部防級地理學者A.赫脫納及其追随者 的錯呇，就在於把經淿地理與自然地理混闰看待 第同一性犋的“統一的”地理學。機械地割裂 “時間”“空間”, 把地理學說成一種單純研究“空 間”的科學, 肐離時代, 䀝離社會, 不區別自然 地理與經濟地理, 並浑用自然地理的變化規律, 來說明經游地理。

經㴒地理學與自然地理學的共同處：首先在 於二者都是硼究“區域”的科學，自然地理學研究

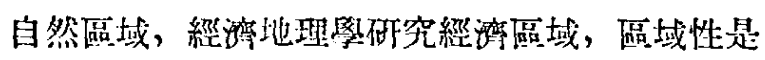
湄一種利學的共闹的特性。其次，在改造自然的
工作中, 自然地理學者與經㴼地理學者要並局地 共同工作，互相配合，拈能起很大的作用; 自然 地理學者在了解一個地區的自然環境的模化展 規律, 学握自然環境的非點之後, 經濟地理學者 就接着研究如何在逜個地區進行正確的經游措 施。由於椡會主義與人民民主國家制度的優越性,

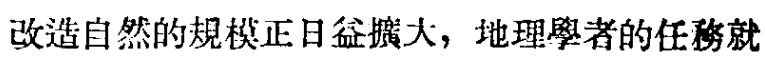

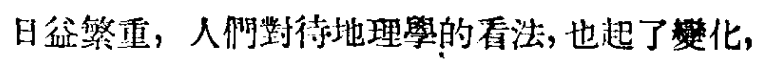
使地理學成第在國家建設中有重大意義的科學。 經济地理學者與自然地理學者正以不同的工作方 法, 隶解决败造自然的共同任務。

在蘇聯, 過去會有一部分學者, 過份强調了 自然地理與經游地理的分離性, 涗一者很少關係, 是网種完全不相同的科學，到後來登明這㧼提法 是阻擬了這二部門科學的進步，而不是慗勋它們 發展, 由此而受到批阡。所以, 必須認識: 經㵂 地理學與自然地理學研究的對象與方法是网樣 的, 而其研究任務是一致的。它們是密切關聯、 互相倚靠的地理學的兩個部門。

\section{二、地理區域劃分的原則}

劃分地理區域是地理學者的一個基本工作。 不同地厤所存在的複雜現象, 必须選摆典型, 劃 
分成幾個區域，這樣才便於科學研究，也梴於國 家建設工作的實際措施。

但㺫現在，在蘇聯，還沒有一個統一的第人 家所公認的地理分區標準。實際劃分一個地區， 造個人如此劃法, 另一個人又是一種劃法。

但是分匰的原则，不外下迅二點：

1. 根晨一定的現筫目的，淮行劃區，例如篇 了防止土壤侵玲進行劃區, 就要研究土壤㻏饳的 主要條件，在各地區間的差别性。在逼個區域，可 能因氣候條件差而侵刢嚴重; 在另一個地區, 可 能因地形紧件差而冲刷劇烈。就這樣, 根據土壤 侵触的特點、土埕侵蝕的主要條件, 而進行分區, 以隻在同類區域進行防止土培侵蚛的同類措施。 其他如篇了防旱, 篇了防洪, 而進行劃區, 性筫 是同樣的。

2. 根據地區的特點, 進行劃區。自然浯域按 照各種自然條件錯棕表現的特點, 經濟區域按照 經流弡展的特點淮行劃區。

敖分篇幾個區域，如何在大單元中劃小單元， 運也根據劃匰者的劃區任䅂而定, 不能强求一 律。

桱流區域劃定以後, 由於圆家建設的高蔚, 新的重大的經湾現象的出現, 各地茄間經濟院合

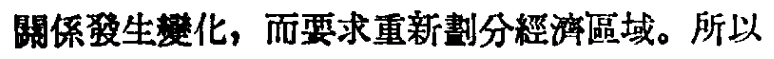
經沾虽不是固定不督的。

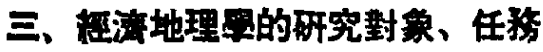 興方法}

蘇聯地理藇界對於䅔沾地理學研究對象問題 的了解是不一致的, 迄今還在討論之中, 而沒有 取得統一的意見。

大體有二種主張。一種主張: 經橓地理學的 研究對象就是㣂會的生座配置。另一種主張：經 漓地理學的研究對象是經流區域。

主張生㕍配置篇經沾地理學研究對象的觀 點, 在蘇聯很普淈, 一直灌注到大學經湾地理敉 學內容中。造個觀點的優點, 在於科學對象和性 質明確, 容易被人接受。在十月革命以後, 薢聯 政府號召科學家研究怎樣進行工業的合理配藓, 當時新荫芽的經淯地理學者, 多數是經湾學者出 身的, 淦應了政府的號召, 研究了不同社會中生 産配置的不同規律, 在大學內從事經濟地理敉學,

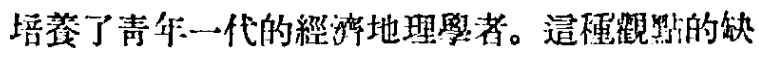
㙳主要是與政治經摔學的界限不清楚，㠺别是與

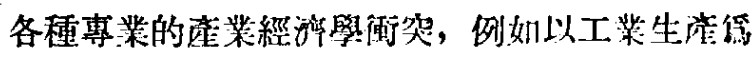

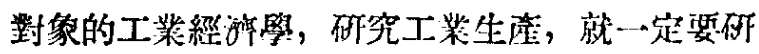

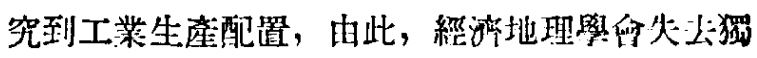

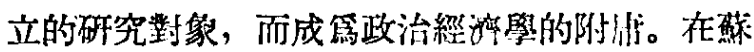

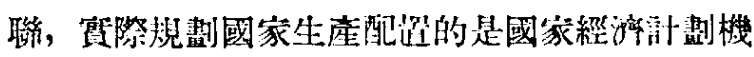
關, 负責人都是經滦學者, 而絰游地理學家很少 參加, 經湾地理學家只限於在大學中喆吹宣傳, 也就是說，對於國家生産配识的筫践，經沙地理 學家直接給予的影響不入。在工作方法上，研究 生産配造易於侧重統計資料的分析, 會脱離卧地 的調柾研究工作。

第二種意胃是三十年代莫斯科大學紃济地理

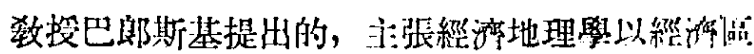

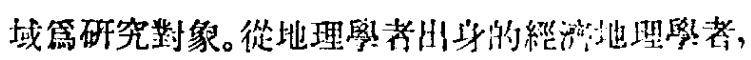

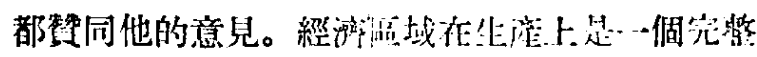

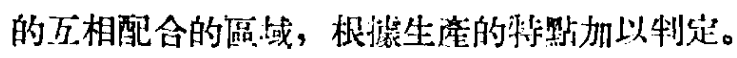

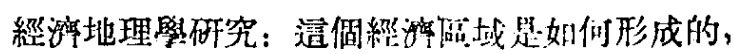

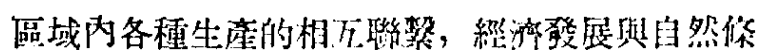

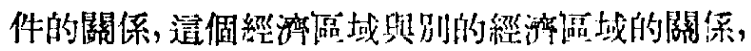

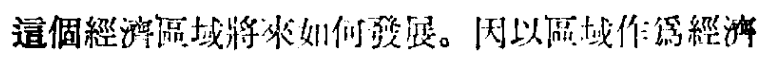
地理學的研究對缘, 經伩地理研究就比較具僼, 必須根搌地圖淮行工作，必須做野外调枮，搜集 實際材料，比較地能够紹合算際情况。

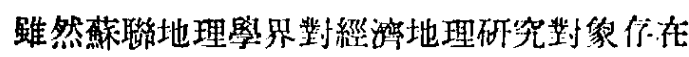
着分岥的意胃。但具體工作任務则汥有多少客别， 除開教學工作外，有以下穖種工作:

1.詮明國家經湾地理情况，供建设部門參考。

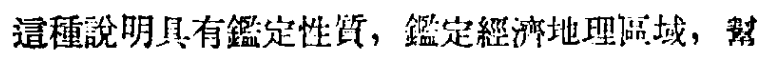

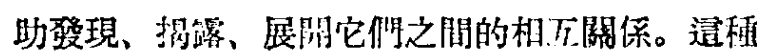

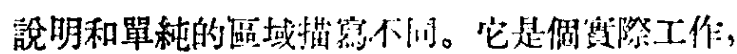
對國家計劃機關捉供參考株科, 如做得好, 對國 家建設的䀬助就很入。

2.調查研究一個地㶾的現有條作, 如何更好 地利用自然環境永發展這個澡域。這檨的工作, 蘇聯經流地理學者做得坟多，大多是配合國家尘 產部門的要求進行的, 如對一個海場進行吥究，

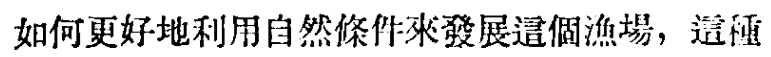
工作，易見成效，經济地理學者也最有興倳。

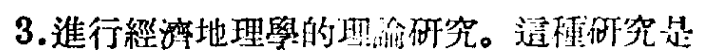
篇了發展這門利學，篇了这好地使用理崤武器來 
發能經沾地理學。進行理論研究要從嘪際出發, 而不是坐在房間裹空想。

4. 參加斯大林改造自然計劃的偉大建設工 作。這是一個新的工作, 要把不利的自然條件改 戀篇有利的自然條件。改造自然就必須認湆自然, 因此這樣工作, 經濟地理學家浀和自然地理學家 密切聯熬, 一迠進行。

研究經济地理學的方法, 首先在於以娠史的 態度研究它。其次是了解熟晳國內外經济地理事 望分佈情况, 就是要運用地圖, 進行野外調查, 搜集材料。第三是要特別注意自然條件與經濟峧 展的關係。

\section{四、自然地理舅的對象、任務與方法}

䱎聯學者關於自然地理學的研究對㪉問題, 踓然也有些等論, 但浔有經济地理學那樣分岐, 基本上都以自然䠰域篇研究對象。由於氣候、地 形、水交地理、土壤地理、生物地理等各專門科 學的發展, 自然地理學者研究一個回域, 不在於 分析地研究, 而在於綜合地研究, 研究自然區域 内各種自然條作綜合表現的特點, 即區域景觀, 據此以劃定自然區域。

由於自然地理學的各個專業學科發展比較成 熟, 因此自然地理的各個學科之間, 各學科與普 通自然地理之間分工的爭論也較少。普通自然地 理的研究方法, 首先是在於綜合地進行研究。

\section{五、國家地理的任務與內容}

國家地理是地理學中新興的一門科學，任䅂 是研究外國地理。在蘇聯科學院地理研究所中, 設有人牫比主國家地理與資本主義國家地理二 組。硼究人民民主國家地理的目的, 是向蘇聯人 地筑㙞介紹䧟些國家的地理情况, 改造自然與經 涼建设的成就，阔朋這些國家社會制度的優越性， 加强和平民主訷營間的友愛團結。

對於资本主義國家地理研究的目的，在於揭 蕗資本主峩测度的管朽性和必然趋於死亡。資本 主義國家對行自然, 不是合理的利用改造自然, 而是破壞與擦您自然, 如濫伐森林而引致嚴重的 土烄侵蚛。照断缷本家篇追求最大限度的利潤, 力罒挑墢新的戰争, 畸形發展軍事工業, 厥迫國

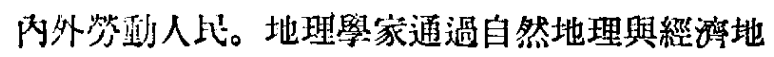

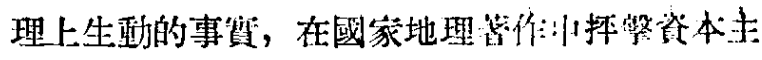
義酸瑟制度。

因此, 國家地理學的價倄在於宣傳敉育, 而 不在於經游建設, 它具有明確的任務與目標。

國家地理的研究工作, 此較困難, 因篇研究 外國地理, 不像研究自己祖國的地理可以隨時進 行考察, 賽際地看到許多研究的事物; 在國內所 能嫂集的外國地理材料, 也不像本國地理材料那 樣豐富。但是這個工作, 既然是篇人民所需要的, 不論困難多大，也必須進行。

\section{六、在地理教舅中如何贯徽鼠國 主裁的政治思想教育}

地理敉學中，應該貫徹敩國主義思想敉有， 而且是完全能够做到的。

在自然地理㸚學中，貫徹敉國主義政治思想 数有, 就在於說明租國自然地理有些什㦄俊越的 條件。對比社會主義、新民主主義國家與資本主 義國家對待自然的不同態度。在資本主義國家裹， 自然環境被濫髲破壞, 森林日漸城少, 河流在閏 水啖, 良好的土地由於土堆侵玲的嚴重而淪於荒 無。而鮛聯與人民民主各國, 則在實行着改造的 計劃, 運用自然力量篇社會服務, 不斷地改變着 自然界的面貌, 把不利的自然條作策有利的自 然條件。每個敉員從這點出棂, 就可以鼓舞學生 的愛國熱情。

經学地理教學中的政治思想敉育, 內容就更

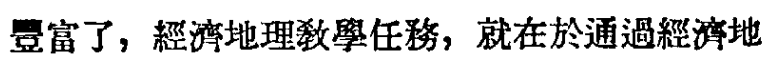
理的具體材料揭發資本主義制度的望朽性, 說明 資本主義制度的必然涩落, 相對地, 通過蘇聯與

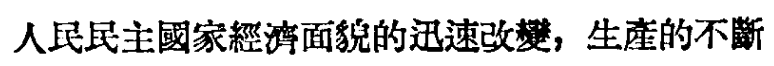
㙁長實例，說明和會主義與新民主主義的传越 性。

\section{七、地理鼠內容度泛，不易精通，研究 地理, 各方面都接觸一些, 而不能 深入，如何才能避免虐荠的毛病?}

的確，地理學的接触面很度，阴類很多，但 不能說地理學是清淺的。因篇地理學中有一系列 的分支, 一系列的軎業化。如自然地理中分篇楊 候、地形、水文地理、土壤地理、生物地理各專 業。每個專業都有它自己的專阿對象、刚容與專 
門的工作方法。不能說逜些專業地理學科是䁹淺 的。

可能存在着虞淺問題的是綜合自然地理與称 合經湾地理。但如果認識了綜合自然地理與綜合 殌浑地理的性質與任務之後, 這個問題也汥有了。 綜合自然地理與綜合經流地理的任務, 在於倚筷 各個專業地理研究工作, 總結與棕合各種專業地 理知識。自然界的各種現象都是相互聯熬、相笛。 故約的, 在㭴過各種專業科學分析研究之後, 必須
進行棕合以認裸自然界總的特點。不論專業地理 的工作做得怎樣詳細, 經過称合研究之後, 仍會 提出許多新的問題的。做棕合工作需要很高的科 學水平，不能說它是膚淺的。

當然綜合地理研究工作, 不是每個地理工作 者都能担當得了。也不能在大學地理系學生中, 就培苓好這種人才，必須挑選基礎較好、興趣較 廣、思想性高並有組織能力的人，在研究機關中! 有意識地加以培養。

\section{通一期的至要內容}

亚一期，設表了關於中國數學、動物學、生 理學、植物學和土壤學現弲的一些文章，以後還 將陸综發表造類性質的稿件。這些文章，在作者 埶筆以前,一般是經過集能討論的, 也就比較能 全面地反映這門科學在中國發展的情况。對新中 國各門科學作出咳樣的叙远，還是初次; 因之， 不可避免地會有很多缺點。這些文音中，有一部 份逼進一步提出了今後本門科學㡎展的方向和工 作的重點; 對於這些意見，需要展開塂泛、深入 的討諭，因第這是關係到今後一個相當長時期內 中國某些部門科學的發展的問題, 希㘹各個崗位 上的科學工作者都能參加造個討論。

中國科學院長春綜合研究所對於國家的建設 方作，曾有過很多成樍，在技術科學研究方面， 也接調到許多新的問題, 如研究題目的選摆、研 究成果的推廣、中間工做的工作等, 逜一期中刊 载的 1952 年研究工作的初步總結, 是可供給其他

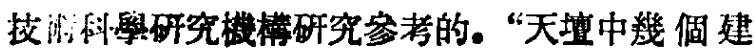

築物的聲學問題”，科學地分析了我國兑代勞動 人民的天方創造。，像這一類的文辛，是會引起 廣泛的興趣的。

蘇聯科學院院長汪斯米掦萑大的“1953 年的 蘇聯科學”、副院長巴雨金的“第人地服務的蘇聯 科學”、土麻曼共和國科學院院長别爾德也复的 “土庫曼大運河區科學研究工作的目前情况和欮 途”等文, 具能地介紹了在偉大的其紊主義建設中 蔡聯科學研究機構和科學家工作的情况, 生顼地 說明了科學在蘇憏的地位和今天的任務。“論刢造 性合作的一些問題”，提出了技術科學研究的任 務問題, 批制了在科學和生赝合作中, 片泊地把 科學研究機構看作是生產單位的附湢機權, 在利 學研究中被動、短視的現象。這樣的現像，在我 們的某些科學研究機構要也是多少作在着的。

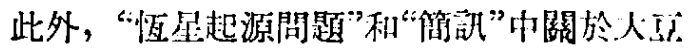

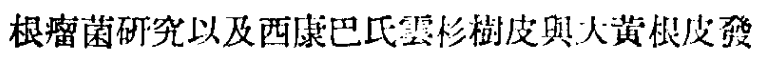
現含有大量鞂酸的報導, 都是们得特别注意的。 